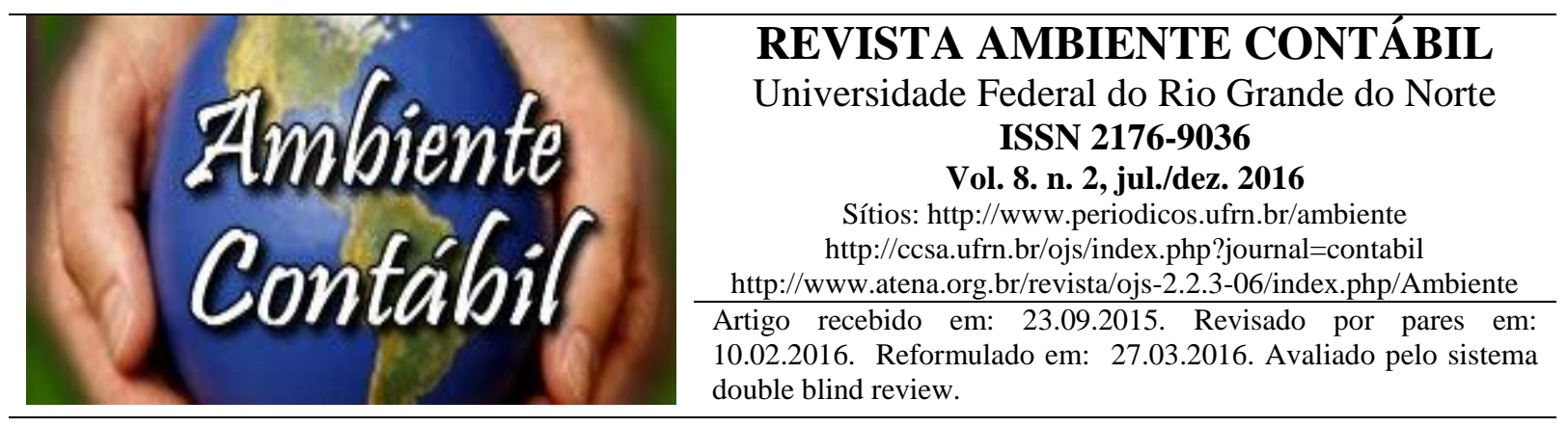

\title{
GESTÃO DO CAPITAL INTELECTUAL: ESTUDO DE CASO EM UMA UNIDADE DE AUDITORIA DO EXÉRCITO BRASILEIRO
}

\section{INTELLECTUAL CAPITAL MANAGEMENT: A CASE STUDY IN BRAZILIAN ARMY AUDIT UNIT}

\section{GESTIÓN DE CAPITAL INTELECTUAL: UN ESTUDIO DE CASO EN UNA UNIDAD DE AUDITORÍA DE EJÉRCITO BRASILEÑO}

\section{Autores}

\section{Alexandre Fernandes Monteiro}

Especialista em Gestão Pública - Mestrando em Ciências Contábeis na Universidade do Vale do Rio dos Sinos - Programa de Pós-Graduação em Ciências Contábeis. Endereço: Av. Unisinos, 950, Bairro Cristo Rei, São Leopoldo - RS - Brasil. CEP: 93.022-000.

Telefone: +55 (51) 3590-8186.

E-mail: prof.alexandremonteiro@gmail.com

\section{Carlos Alberto Diehl}

Doutor em Engenharia de Produção - Professor da Universidade do Vale do Rio dos Sinos Programa de Pós-Graduação em Ciências Contábeis. Endereço: Av. Unisinos, 950, Bairro Cristo Rei, São Leopoldo - RS - Brasil. CEP: 93.022-000. Telefone: +55 (51) 3590-8186 E-mail: cd@unisinos.br

\section{Paulo Roberto Reichelt Ayres}

Especialista em Perícia e Auditoria - Mestrando em Ciências Contábeis na Universidade do Vale do Rio dos Sinos. Programa de Pós-Graduação em Ciências Contábeis. Endereço: Av. Unisinos, 950, Bairro Cristo Rei, São Leopoldo - RS, CEP: 93.022-000. Telefone: +55 (51) 3590-8186

E-mail:pra_73@yahoo.com.br

\section{Sandra Belloli de Vargas}

Especialista em Marketing - Mestranda em Ciências Contábeis pela Universidade do Vale do Rio dos Sinos - Programa de Pós-Graduação em Ciências Contábeis. Endereço: Av. Unisinos, 950, Bairro Cristo Rei, São Leopoldo - RS - Brasil. CEP: 93.022-000. Telefone: +55 (51) 3590-8186

E-mail: sandrabelloli@terra.com.br 


\title{
RESUMO
}

O capital intelectual (CI) é percebido pelo mercado e por estudiosos como um fator decisivo no desempenho das empresas, sobretudo em negócios altamente dependentes do fator humano. Em uma atividade cuja principal fonte de criação de valor é o conhecimento, como a auditoria, um modelo capaz de permitir o controle e gestão de seu CI é ferramenta relevante. Este trabalho buscou verificar como o Exército Brasileiro identifica, mensura e faz a gestão do CI em uma de suas unidades de auditoria interna. A partir de estudo de caso único, apoiado em um protocolo, realizaram-se entrevistas com auditores e gestores militares, complementadas pela percepção dos auditados sobre o trabalho do auditor interno, cujos dados foram consolidados por meio de matriz de análise de conteúdo com vistas a se verificar como é feita a gestão do CI. Verificou-se que os gestores percebem a importância do CI, porém seguem um modelo de gestão superficial, sem uso de indicadores ou ferramentas, baseado na intuição, com baixo potencial de conexão com a estratégia organizacional. Diante desse resultado e com base no CI identificado e na literatura, foi proposto um modelo com vistas a possibilitar a sua mensuração, registro e gestão.

Palavras-Chave: Capital intelectual. Auditoria interna. Controle interno. Exército Brasileiro.

\begin{abstract}
Intellectual capital (IC) is perceived by the market and by scholars as a decisive factor in business performance, especially in heavily dependent on business of the human factor. In an activity whose main source of value creation is knowledge, such as auditing, a model that allow the control and management of intellectual capital is relevant tool. This study aimed to verify how Brazilian Army identifies, measures and manages IC in one of its internal audit units. From single case study, supported by a protocol, we conducted interviews with auditors and military managers, complemented by the perception of audited about the work of internal auditor, whose data were consolidated through content analysis matrix with a view to check how works the IC's management. It was found that managers realize the importance of IC, but follow a model of surface management, without using indicators or tools, based on intuition, with low potential connection with organizational strategy. These finding and based on the IC identified and literature, a model to measurement and management was proposed.
\end{abstract}

Keywords: Intellectual capital. Internal audit. Internal control. Brazilian Army.

\section{RESUMEN}

El capital intelectual es percibido por el mercado y por los estudiosos como un factor decisivo en el rendimiento del negocio, especialmente en negocios muy dependiente del factor humano. En una actividad cuya fuente de creación de valor principal es el conocimiento, tales como la auditoría, un modelo que permite el control y la gestión de su capital intelectual es la herramienta relevante. Este estudio tuvo como objetivo verificar cómo identifica el Ejército de Brasil, medidas y gestiona el capital intelectual en una de sus unidades de auditoría interna. De estudio de caso único, apoyado por un protocolo, se realizaron entrevistas con los auditores y gerentes militares, complementado por la percepción del auditado sobre el trabajo del auditor interno, cuyos datos se consolidaron através de matriz de análisis de contenidos con el fin de comprobar cómo es la gestión del capital intelectual. Se encontró que los gerentes se dan cuenta de la importancia del capital intelectual, pero siguen un modelo de gestión de la superficie, sin necesidad de utilizar indicadores o herramientas, basadas en la intuición, con baja posible relación con la estrategia organizacional. Teniendo en cuenta este resultado y en base a la CI identificado en la investigación y la literatura, se propuso un modelo con el fin de permitir su medición y gestión.

Palabras clave: Capital intelectual. Auditoría interna. Control interno. Ejército Brasileño. 


\section{INTRODUÇÃO}

A economia mundial tem evoluído de uma sociedade industrial para uma sociedade do conhecimento em cuja gestão do capital intelectual (CI) está presente nas organizações que fazem uso intensivo de conhecimento dinâmico e complexo (ANTUNES, 2006). Para Dias, Zarelli e Selig (2013), a gestão pública deve se inserir neste contexto de forma a tratar eficazmente os problemas relacionados ao orçamento, desenvolvimento regional, sustentabilidade de políticas públicas, dentre outras ações de interesse público.

Antunes (2006), diante da expansão acelerada do conhecimento nas organizações, questiona o papel da Contabilidade, principalmente das implicações da mensuração dos elementos intangíveis e, consequentemente, do CI. Polo e Rodriguez (2014) questionam o motivo pelo qual somente uma reduzida parcela de organizações faz a gestão de seus intangíveis, aí incluído o CI, se estes são considerados tão importantes. Uma explicação para essas questões, segundo Antunes (2006), pode estar na natureza abstrata desses elementos que são gerados por componentes igualmente intangíveis, tendo o conhecimento tanto como insumo, quanto como produto e que devem ser vistos isoladamente e também no conjunto.

Nesse contexto, a gestão do CI apresenta-se como um fator determinante em organizações, sejam elas públicas ou privadas, principalmente em um negócio que tem no conhecimento humano a sua maior fonte de valor. $\mathrm{O}$ produto de organizações profissionais baseadas em serviços intensivos em conhecimento, como auditoria, não é medido em termos físicos como toneladas, unidades e litros e, nem mesmo o número de horas dispendidas por um auditor em um trabalho de campo, caracterizam um output, mas um input (ANTHONY; GOVINDARAJAN, 2007).

O Exército Brasileiro (EB) realiza investimentos em CI, conforme se verifica em seu orçamento planejado para o ano de 2014, em que foram destinados cerca de 7,5\% dos gastos projetados para custeio da Instituição. São gastos visando à capacitação profissional militar, treinamento de combate, formação e aperfeiçoamento de engenheiros militares $\mathrm{e}$ desenvolvimento tecnológico, conforme dados do Projeto de Lei Orçamentária Anual para o exercício financeiro 2014 (BRASIL, 2014). A gestão do CI na atividade de auditoria interna no EB insere-se neste orçamento, pois a Instituição necessita investir na capacitação de seus auditores e na implantação de tecnologias com vistas a potencializar seus resultados.

Este trabalho busca contribuir ao trazer dados de um setor da economia cuja maior parte do valor origina-se da produção de serviços e, conforme Guthrie e Dumay (2015), representa uma lacuna a ser explorada no contexto da pesquisa sobre o CI, especialmente no que se refere à teoria normativa e seus aspectos de mensuração e contabilização. De acordo com Dumay, Guthrie e Puntillo (2015), há uma oportunidade para desenvolver e testar estruturas e modelos de CI em contextos específicos do setor público. Ainda, conforme revisão de literatura sobre CI no setor público feita em um período de 5 anos (2010 a 2015) em 8 periódicos de contabilidade reconhecidos internacionalmente, não há estudos com foco em auditoria.

Nesse sentido, a pergunta a ser respondida pela pesquisa é: se o EB reconhece a importância do CI, quais as técnicas utilizadas pela Instituição para identificá-lo, mensurá-lo e geri-lo em uma de suas unidades de auditoria interna? Para atingir esse objetivo de pesquisa, este trabalho foi organizado por meio desta introdução, de um referencial teórico, de uma seção que descreve o método e de outra com os resultados e discussões, finalizando com considerações finais.

Verificou-se que a unidade pesquisada reconhece a importância do conhecimento humano, das relações necessárias à sustentação da organização e da manutenção de uma estrutura capaz de dar fluidez às informações o que, em outras palavras, trata-se do CI. No entanto, a unidade não o identifica como um ativo e, portanto, não o mensura o que conduziu 
a pesquisa a propor um modelo baseado em padrões estabelecidos pela literatura e instituições de contabilidade e auditoria (IIA, 2012; SARENS 2009, ALVES, 2013; IFAC, 2014; BRASIL, 2014) e em um formato prescrito pela literatura sobre CI (EDVINSON; MALONE, 1998; FRANCINE, 2002; ANTUNES, 2006; GUTHRIE; STEANE; FARNETI, 2009; MALAVSKI; LIMA; COSTA, 2010; VELTRI, 2014; VAGNONI; OPPI, 2015; MASSINGHAM; TAM, 2015; CHIUCCI; DUMAY, 2015).

\section{REFERENCIAL TEÓRICO}

\subsection{GESTÃO DO CAPITAL INTELECTUAL (CI)}

Antes de se definir CI, é necessário entender sua relação com os intangíveis. Stewart (1998) considera o CI um intangível caracterizado pelo somatório do conhecimento de todas as pessoas em uma empresa. Portanto, para este autor, o CI é uma parte dos intangíveis. Malavskia et al. (2010) abordaram os intangíveis pela ótica da Visão Baseada em Recursos (VBR) e forneceram uma lista de ativos intangíveis: direitos de propriedade intelectual, banco de dados, licenças, softwares, concessões, goodwill, relacionamentos internos e externos, força de trabalho, tecnologia, habilidades, dentre outros.

Para Lima e Antunes (2012), o CI é o produto proveniente da aplicação das habilidades dos membros da organização com a finalidade de trazer vantagem competitiva materializada em bons relacionamentos com clientes e no desenvolvimento de novas tecnologias. Estas habilidades, na visão de Anthony e Govindarajan (2007), não são repetíveis e não é possível reproduzi-las de forma a se construir projetos comercializáveis no formato de pacotes padrão. Lima e Antunes (2013), entendem o CI como um estoque estruturado e o aprendizado organizacional é concebido na forma de processo dinâmico de renovação estratégica ocorrendo em nível do indivíduo, do grupo e da organização.

O CI, na ótica da VBR, é medido em três perspectivas: capital humano, capital relacional e capital estrutural. O capital humano abrange o conhecimento de posse dos funcionários da empresa, como o know-how e a especialização técnica. O capital relacional é o somatório de todos os recursos necessários à viabilização das relações externas da empresa com consumidores, fornecedores, parceiros, investidores, stakeholders. O capital estrutural é a espinha dorsal da organização e subdivide-se em propriedade intelectual e ativos de informação, constituindo-se do planejamento administrativo e sistemas de controle, dos processos, das redes, das políticas e da cultura (MALAVSKI; LIMA; COSTA, 2010).

A gestão do CI deve ser precedida pela identificação e mensuração de seus componentes, pois, se ele não é identificado, não pode ser medido e, consequentemente, não pode ser gerido. Em termos relativos, empresas de serviços profissionais, como auditoria, possuem, relativamente, poucos ativos tangíveis e as habilidades de seus auditores não consta das demonstrações contábeis o que exige a criação de um modelo capaz de mensurá-las (ANTHONY; GOVINDARAJAN, 2007).

Por que criar relatórios para o CI? Para James, Peter e Federica (2009) há demandas distintas entre os que buscam informações nos relatórios tradicionais e os usuários dos dados sobre CI. Guthrie, Steane e Farneti (2009) entendem que o movimento pela sustentabilidade tem reafirmado a crítica ao modelo de demonstrativos financeiros tradicionais por proverem informações contábeis incompletas sobre a performance organizacional. O uso da lógica de mercado em organizações sem fins lucrativos para a medição do CI não tem apresentado os resultados demandados em função das exigências que o setor exige em termos de transparência e accountability (GUTHRIE; STEANE; FARNETI, 2009).

Chiucchi e Dumay (2015) consideram a divulgação do CI de empresa pública um instrumento que complementa os demonstrativos financeiros e de sustentabilidade e permite 
uma visão completa (financeira, ambiental e dos recursos intangíveis) de como a organização adiciona valor para seus stakeholders. No entanto, a implementação de um sistema de medição é um processo lento e de convencimento até que se rotinize a apresentação de uma demonstração que efetivamente explicite o CI de uma organização. Os autores criticam a ideia de que o foco na busca da contabilização do CI tira da organização a energia necessária para geri-lo (CHIUCCHI; DUMAY, 2015).

Nesse contexto, os sistemas de gestão integrados e específicos para a gestão dos elementos intangíveis são ferramentas úteis. Trata-se de sistemas estruturados para identificar, mensurar, registrar e avaliar a contribuição do CI para a geração de valor das organizações. Esses sistemas podem ser alguns daqueles já existentes, elaborados segundo a filosofia do Balanced Scorecard (BSC) ou Navegador da Skandia, ou aplicativos desenvolvidos pelas empresas (ANTUNES, 2006).

Francine (2002) sugere a combinação de indicadores tradicionais com medições que tragam outras percepções (relação causal entre processo de gestão do conhecimento e a geração de valor ao acionista, ou esforços voltados para a mensuração do valor do ativo intangível/capital intelectual) com o objetivo de se criar novos tipos de indicadores de desempenho capazes de orientar a gestão de negócios. $\mathrm{O}$ autor considera que esse indicador traduzirá o potencial do negócio em gerar fluxo de caixa futuro e que este valor projetado deve ser trazido a valor presente e será equivalente ao valor do negócio (FRANCINE, 2002).

Antunes (2006) entende que tanto a mensuração quanto a gestão do CI constituem-se em processos de avaliação, pois irá proceder-se a um julgamento sobre algum atributo. Assim, os modelos de gestão do CI, além de contemplarem a identificação, mensuração e registro desses investimentos, devem acompanhar a sua evolução de forma a captar a expectativa de retorno desses ativos. A implementação e operacionalização desses modelos podem se dar por meio dos Sistemas Integrados de Gestão (SIG) ou Enterprise Resource Planning (ERP) ou por aplicativos desenvolvidos especificamente para essa finalidade (ANTUNES, 2006).

Sveiby (1998) classifica o valor dos ativos intangíveis de uma organização em três grupos: competência do funcionário, estrutura interna e estrutura externa. Segundo Sveiby (1998), não existe um sistema de medida financeira abrangente de avaliação de ativos intangíveis que seja prático e útil para os gestores. Para Chiucchi e Dumay (2015), na maioria dos casos, os dados necessários à mensuração do CI já se encontram nos sistemas de gestão e controle, sendo necessário convencer os gestores sobre o ganho em valor para a organização e para os próprios funcionários advindo de sua exploração sistematizada.

Alvarenga, Barbosa e Pereira (2007) pesquisaram três empresas e o resultado foi no sentido de a avaliação das práticas da gestão do conhecimento, suas métricas e indicadores, envolver um misto de elementos qualitativos e quantitativos, criação de novas práticas e uso de modelos reconhecidos, como o BSC, valor econômico agregado (EVA), e de indicadores como número de ideias por especialidade, número de horas por ano de educação continuada e capacitação, dentre outros.

De acordo com Edvinsson e Malone (1998), para uma ferramenta medir o CI com eficiência, necessita realizar três tarefas: (i) indicar a posição, a direção e a velocidade da organização, (ii) visualizar sob a ótica de um patamar elevado, de forma a criar metaíndices comparáveis aos resultados obtidos nas demonstrações financeiras; (iii) permitir uma interpretação facilitada por parte dos usuários da informação. É desejável que a ferramenta tenha um formato dinâmico, capaz de fazer a leitura atual do CI de forma imediata e a qualquer tempo, detectando o estado de euforia, exaustão, stress, fraqueza e enfermidade de uma empresa, desempenho este ainda não atingindo pelos modelos disponíveis.

Para Alves et al. (2014) a medição do capital intelectual se encontra em processo de aperfeiçoamento e entre os modelos mais utilizados nas pesquisas estão: (i) diferença entre o valor de mercado e o valor contábil; (ii) razão entre o valor de mercado e o valor contábil 
(market-to-book); iii) "Q" de Tobin; (iv) navegador do Capital intelectual - modelo Stewart; (v) modelo de Edvinsson \& Malone (modelo Skandia); (vi) modelo de Sveiby; (vii) modelo heurístico, e (viii) os indicadores propostos por Martinez, Guthrie, Marques e Simom.

O Navegador Skandia é um modelo capaz de produzir um relatório de avaliação cujas medidas são organizadas em cinco dimensões: financeira, do cliente, dos processos, da renovação e desenvolvimento e humana (MALAVSKI; LIMA; COSTA, 2010). Apropriandose da metáfora de uma casa, Edvinsson e Malone (1998) descreveram as dimensões ou focos do Navegador. Cada uma das dimensões do Navegador possui indicadores e esses traduzem numericamente algum aspecto da organização. O Quadro 1 apresenta exemplos de indicadores utilizados no modelo Skandia que podem ser adaptáveis ao setor público.

Quadro 1 - Indicadores do Navegador Skandia adaptáveis ao setor público

\begin{tabular}{|c|c|c|}
\hline DIMENSÃO & $\begin{array}{c}\text { INDICADOR (preferencialmente em } \\
\%)\end{array}$ & $\begin{array}{l}\text { APLICAÇÃO NO SETOR } \\
\text { PÚBLICO }\end{array}$ \\
\hline Financeira & 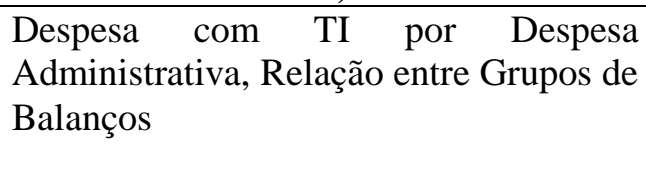 & $\begin{array}{l}\text { No planejamento e controle da } \\
\text { execução do orçamento público } \\
\text { em atendimento ao equilíbrio } \\
\text { fiscal }\end{array}$ \\
\hline $\begin{array}{l}\text { Clientes/Estrutura } \\
\text { Externa }\end{array}$ & $\begin{array}{l}\text { Número de Clientes por Funcionário, } \\
\text { duração média do relacionamento com o } \\
\text { Cliente }\end{array}$ & $\begin{array}{l}\text { No controle da efetividade da } \\
\text { relação com os clientes }\end{array}$ \\
\hline $\begin{array}{l}\text { Processos/Estrutu } \\
\text { ra Interna }\end{array}$ & $\begin{array}{l}\text { Despesa Administrativa por Ativos } \\
\text { administrados, PCs e Laptops por } \\
\text { empregado, Quantidade de Serviços por } \\
\text { Cliente, Custo dos Erros } \\
\text { Administrativos }\end{array}$ & $\begin{array}{l}\text { No acompanhamento e controle } \\
\text { da efetividade dos processos na } \\
\text { geração de riqueza }\end{array}$ \\
\hline $\begin{array}{l}\text { Renovação e } \\
\text { desenvolvimento }\end{array}$ & $\begin{array}{l}\text { Investimento em P\&D por Investimento } \\
\text { Total, Percentual de Horas de } \\
\text { Treinamento, Despesa de Capacitação } \\
\text { por Empregado, } \\
\text { Percentual de Horas Dedicadas ao } \\
\text { Desenvolvimento }\end{array}$ & $\begin{array}{l}\text { No controle dos esforços no } \\
\text { sentido de se criar novos produtos } \\
\text { e na melhoria da qualidade dos } \\
\text { serviços públicos prestados à } \\
\text { sociedade }\end{array}$ \\
\hline $\begin{array}{l}\text { Humana/Competê } \\
\text { ncias }\end{array}$ & $\begin{array}{l}\text { Índice de Rotatividade, Média de Anos } \\
\text { de Experiência dos Funcionários, Índice } \\
\text { de Novatos }\end{array}$ & $\begin{array}{l}\text { No controle do quadro de } \\
\text { servidores públicos }\end{array}$ \\
\hline
\end{tabular}

Fonte: Adaptado de Sveiby, 1998; Stewart, 1998; Edvinsson; Malone, 1998.

A pesquisa de Guthrie, Steane e Farneti (2009) identificou no relatório de CI da Australian Red Cross Blood Service (ARCBS) um framework em três dimensões (capital interno, externo e humano), contendo 32 componentes.

Os demonstrativos do CI da Cruz Vermelha australiana entre 2002 e 2005 apresentaram menor ênfase em elementos do capital humano, comparativamente aos demais. Verificou-se que os relatórios de CI estudados não apresentaram um padrão, variando anualmente no formato e nas informações apresentadas, o que dificulta uma análise longitudinal. Há uma grande incidência de elementos reportados referentes a inovação em função do interesse pelo programa de pesquisa da organização. Tal característica tem origem na natureza dos usuários da informação (médicos e investidores da área médica) (GUTHRIE; STEANE; FARNETI, 2009). 
Quadro 2 - Componentes do CI da Australian Red Cross Blood Service

\begin{tabular}{|l|l|l|}
\hline \multicolumn{1}{|c|}{ CAPITAL INTERNO } & \multicolumn{1}{|c|}{$\begin{array}{c}\text { CAPITAL } \\
\text { EXTERNO }\end{array}$} & \multicolumn{1}{c|}{ CAPITAL HUMANO } \\
\hline 1. Filosofia de gestão / & 9. Nome da & 19. Educação financeira \\
cultura & organização / marcas & 20. Formação \\
2. Estrutura & 10. Alianças e & 21. Aprendizagem e desenvolvimento \\
organizacional & parcerias & 22. Inovação \\
3. Processos de Gestão & 11. Licenças / & 23. Número de empregados / Demografia \\
4. Políticas e & franchising & 24. Competências relacionadas com o \\
procedimentos & 12. Canais de & trabalho \\
5. Sistemas de informação & distribuição & 25. Igualdade de oportunidades de emprego \\
/ tecnologia & 13. Contratos & (EEO) / diversidade \\
6. Propriedade intelectual & favoráveis & 26. Participação em comunidade \\
7. Pesquisa e & 14. Comunidade & 27. Relações laborais \\
Desenvolvimento & 15. Clientes & 28. Satisfação do empregado \\
8. Qualidade dos serviços & 16. Fornecedores & 29. Remuneração \\
/ produtos & 17. Consultores & 30. Plano de de carreira / desenvolvimento \\
& 18. Relações & 31. Desempenho executivo sênior e \\
& & resultados \\
& & 32. Conhecimento / competência \\
\hline
\end{tabular}

Fonte: Guthrie, Steane e Farneti (2009).

Por sua vez, o demonstrativo do CI da ANPAS Piemont (OSFL italiana) se divide nas subcategorias capital humano, organizacional e relacional. Este demonstrativo não está incorporado ao relatório tradicional (anual), portanto é formulado e divulgado separadamente. Para Veltri (2014), o demonstrativo do CI apresenta informações diferenciadas das demonstrações tradicionais que o tornam mais valorosas na gestão de organizações sem fins lucrativos. No entanto, no caso da ANPAS Piemont, nos dez anos de relatórios do CI pesquisados não foi verificada a busca pelo atendimento às expectativas informacionais dos stakeholders nem a percepção destes sobre o CI (VELTRI, 2014).

Para Ramirez (2010), os fatores intangíveis são mais presentes no setor público do que no privado o que justifica a aplicação de modelos de gestão do CI. A identificação, mensuração e gestão deste CI permite às entidades públicas perseguirem seus objetivos em melhores condições. Para a autora, o ambiente público é o ideal para a aplicação de modelos de gestão do CI, porém alerta sobre a impossibilidade de generalização dos resultados (RAMIREZ, 2010).

\subsection{O CI E A AUDITORIA INTERNA (COMPETÊNCIAS E ESTRUTURAS REQUERIDAS)}

Na visão de Lelis e Pinheiro (2012) a auditoria interna enfrenta um novo paradigma que se baseia na visão dos processos com foco nos riscos do negócio e nas práticas de governança corporativa. Nesse contexto, conforme Sarens (2009), as exigências técnicas e comportamentais da atividade de auditoria interna requerem elevado nível de pensamento crítico e lógico, capacidade de análise e poder de influência sobre os tomadores de decisão.

Assim, as atuais demandas da função de auditoria interna exigem características técnicas e comportamentais individuais como escolaridade, treinamento, certificações, relacionamento interpessoal e habilidades de comunicação que impactam a qualidade da atividade (SARENS; 2009). Para Lelis e Pinheiro (2012), essas novas orientações encerram o ciclo de relação auditor-auditado baseado em práticas detectivas, policialescas e punitivas cujo produto resumia-se ao relatório de auditoria. 
Segundo o Tribunal de Contas da União (BRASIL, 2009), o Committe of Sponsoring Organizations of the Treadway Commission - COSO publicou na década de 1990 critérios práticos, amplamente aceitos, para o estabelecimento de controles internos e para avaliação de sua efetividade. $\mathrm{O}$ modelo COSO foi incorporado por diversas organizações supranacionais e nacionais de auditoria (AICPA, Intosai, setor público brasileiro) e traz características dinâmicas baseadas no gerenciamento de riscos e em modelos de governança corporativa. Trata-se de um paradigma proativo em cujo papel das auditorias internas governamentais passou a ter um cunho mais voltado para a avaliação abrangente dos controles internos, com ênfase em controles gerenciais e gerenciamento de riscos, deixando de lado a função de mero avaliador da conformidade legal das despesas públicas (BRASIL, 2009).

O IES-8 (Competências Requeridas ao Auditor Profissional), organizado pela International Federation of Accountants (IFAC), traz as competências necessárias ao profissional auditor, conforme o Quadro 3:

Quadro 3 - Competências requeridas ao auditor segundo o IFAC

\begin{tabular}{|l|l|}
\hline \multicolumn{1}{|c|}{ ÁREA } & \multicolumn{1}{|c|}{ COMPETÊNCIA } \\
\hline Geral & Ser qualificado como profissional em contabilidade e ter formação superior \\
\hline Conhecimentos & $\begin{array}{l}\text { Informações históricas (modelos passados) em auditoria financeiras em nível } \\
\text { avançado, contabilidade nível avançado, e tecnologia da informação (TI) }\end{array}$ \\
\hline Habilidades & $\begin{array}{l}\text { Identificação e solução de problemas; uso adequado de instrumentos de } \\
\text { pesquisa; saber trabalhar em grupo; desenvolver e aplicar técnicas de auditoria; } \\
\text { demonstrar capacidade de inquirir e pensar de forma lógica e abstrata e ter } \\
\text { capacidade de análise crítica; demonstrar ceticismo profissional; aplicar } \\
\text { julgamento profissional e se posicionar e apresentar soluçôes diante de conflitos }\end{array}$ \\
\hline $\begin{array}{l}\text { Valores } \\
\text { profissionais } \\
\text { éticos }\end{array}$ & $\begin{array}{l}\text { Capacidade de aplicar no ambiente de auditoria os valores éticos, como } \\
\text { integridade, objetividade, competência e devido cuidado profissional, } \\
\text { confidencialidade e comportamento profissional }\end{array}$ \\
\hline $\begin{array}{l}\text { Experiência de } \\
\text { campo }\end{array}$ & $\begin{array}{l}\text { Experiência prévia (ao menos 3 anos) em atividades correlatas a auditoria como } \\
\text { gestão de informações financeiras, contabilidade que permitam a aquisição de } \\
\text { habilidades para passar a atuar como auditor profissional }\end{array}$ \\
\hline $\begin{array}{l}\text { Desenvolvimento } \\
\text { profissional } \\
\text { continuado }\end{array}$ & $\begin{array}{l}\text { Necessária a pré-disposição ao aperfeiçoamento contínuo para o } \\
\text { acompanhamento da evolução do ambiente auditado }\end{array}$ \\
\hline Avaliações & Necessária a pré-disposição a avaliações periódicas \\
\hline
\end{tabular}

Fonte: IFAC, 2014.

De acordo com o IIA (2012), os auditores devem cumprir os requisitos mínimos de educação continuada estabelecidos por suas organizações e normas profissionais relevantes. Nessa atividade há riscos que envolvem a política, economia, consequências na percepção da opinião pública sobre tratamento justo e equitativo dos cidadãos, meio ambiente, entre outros. Por tudo isso, o trabalho dos auditores públicos carrega um risco de avaliação inserido em seus planos de auditoria (IIA, 2012). Em função desses riscos, para Alves (2013), o auditor público deve reunir competências como liderança e qualificações necessárias para realizar a totalidade das auditorias exigidas pelo seu mandato o que reflete no recrutamento e na gestão de pessoal.

Conforme Sarens (2009), a maioria das normas que tratam de auditoria interna buscam definir um perfil adequado para o auditor baseado nos seguintes aspectos: (i) background educacional, (ii) experiência profissional, (iii) certificação profissional, (iv) educação continuada, (v) habilidades comportamentais, (vi) habilidades técnicas e (vii) competências. Para o autor, é questionável se este perfil é adequado ao gerenciamento de risco e aperfeiçoamento dos controles internos. 
No que se refere ao capital estrutural, de acordo com Chiucchi e Dumay (2015), a estruturação do conhecimento pode acelerar a sua difusão e uso, aumentando as competências do pessoal, o que pode ser feito por meio da gestão de banco de dados corporativo. O uso da TI como alvancador da difusão do conhecimento é um aspecto citado por Sarens (2009). Nesse viés, pesquisa realizada em hospital público europeu, mostrou a importância do capital estrutural como indutor da inovação e que há relação direta entre este e o capital humano (SANTOS-RODRIGUES et al., 2013).

\subsection{ESTUDOS ANTERIORES}

A seguir, apresentam-se estudos que abordaram o tema pesquisado com potencial para servirem de base para modelagem de um sistema de mensuração, registro e gestão do CI.

\section{Quadro 4 - Estudos relacionados}

\begin{tabular}{|c|c|c|}
\hline PESQUISADORES & OBJETIVO & PRINCIPAIS ACHADOS \\
\hline Antunes (2006) & $\begin{array}{l}\text { Investigar a adequação do } \\
\text { Sistema de Informações } \\
\text { Contábeis Gerenciais de } \\
\text { grandes empresas brasileiras } \\
\text { à gestão do CI }\end{array}$ & $\begin{array}{l}\text { A grande maioria dos gestores realiza } \\
\text { investimentos em elementos do CI e } \\
\text { atribuem indicadores para avaliar esses } \\
\text { investimentos, mas não de forma integrada } \\
\text { que permita a quantificação correta dos } \\
\text { valores investidos e a avaliação do retorno } \\
\text { desses investimentos }\end{array}$ \\
\hline $\begin{array}{l}\text { Guthrie, Steane, } \\
\text { Farneti (2009) }\end{array}$ & $\begin{array}{l}\text { O artigo procura analisar as } \\
\text { práticas usadas na confecção } \\
\text { de relatórios sobre o CI no } \\
\text { Serviço Australiano da Cruz } \\
\text { Vermelha de Sangue, } \\
\text { organização sem fins } \\
\text { lucrativos }\end{array}$ & $\begin{array}{l}\text { Indicam um foco maior sobre o capital } \\
\text { interno e externo, com menos foco em } \\
\text { capital humano. A frequência com que } \\
\text { certos elementos de capitais internos, } \\
\text { externos e humanos ocorrem em seus } \\
\text { relatórios varia em função da necessidade } \\
\text { de um pequeno grupo de stakeholders e é } \\
\text { explicada por macro, meso e micro fatores }\end{array}$ \\
\hline Ramírez (2010) & $\begin{array}{l}\text { Apresentar modelos de } \\
\text { desenvolvimento da } \\
\text { capacidade de identificar, } \\
\text { medir e gerenciar seus ativos } \\
\text { intangíveis em organizações } \\
\text { públicas e mostrar a } \\
\text { importância do CI como } \\
\text { instrumentos para enfrentar } \\
\text { os novos desafios no setor } \\
\text { público }\end{array}$ & $\begin{array}{l}\text { Trata-se de uma revisão gestão de capital } \\
\text { intelectual em organizações públicas } \\
\text { espanholas. Com base em } 4 \text { estudos de } \\
\text { caso, o estudo fornece um referencial } \\
\text { prático para organizações públicas com } \\
\text { objetivo de desenvolver meios para } \\
\text { identificar, medir e gerenciar seus ativos } \\
\text { intangíveis }\end{array}$ \\
\hline $\begin{array}{l}\text { Lima e Antunes } \\
(2012)\end{array}$ & $\begin{array}{l}\text { Investigar qual é a percepção } \\
\text { dos gestores de uma indústria } \\
\text { farmacêutica sobre o } \\
\text { conceito de CI e dos fatores } \\
\text { que são relevantes para se } \\
\text { realizar a sua gestão sob a } \\
\text { ótica da visão baseada em } \\
\text { recursos (VBR) alinhada ao } \\
\text { seu ambiente econômico }\end{array}$ & $\begin{array}{l}\text { O fator mais relevante para a gestão do CI } \\
\text { na empresa é o gerenciamento dos } \\
\text { processos no sentindo de controlar os } \\
\text { investimentos e avaliar o seu retorno por } \\
\text { meio da utilização de indicadores. Muito } \\
\text { embora os gestores percebam a importância } \\
\text { da gestão do capital intelectual, os mesmos } \\
\text { não possuem ferramentas que lhes auxiliem } \\
\text { nesse processo, visto que a área de } \\
\text { controladoria da empresa ainda não } \\
\text { desenvolveu indicadores de avaliação do CI }\end{array}$ \\
\hline
\end{tabular}




\begin{tabular}{|c|c|c|}
\hline 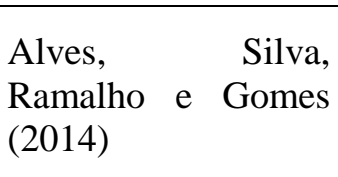 & $\begin{array}{l}\text { Mensurar os indicadores de } \\
\text { capital intelectual } \\
\text { desenvolvidos em um } \\
\text { escritório de contabilidade }\end{array}$ & $\begin{array}{l}\text { Destaca a importância de se investir em } \\
\text { ações para o desenvolvimento do capital } \\
\text { humano, especialmente com vistas à } \\
\text { disseminação do conhecimento. }\end{array}$ \\
\hline $\begin{array}{l}\text { Chiucchi e Dumay } \\
\text { (2015) }\end{array}$ & $\begin{array}{l}\text { Verificar a viabilidade em se } \\
\text { implementar práticas } \\
\text { contábeis em CI ("lock-in") } \\
\text { e, posteriormente, } \\
\text { "desbloqueá-las" através de } \\
\text { uma abordagem de gestão } \\
\text { mais estratégica }\end{array}$ & $\begin{array}{l}\text { A evidência do estudo em uma empresa } \\
\text { pública mostra como, por vezes, um foco } \\
\text { dominante sobre a contabilização do CI é } \\
\text { necessário, especialmente para permitir que } \\
\text { os interessados acessem este CI }\end{array}$ \\
\hline
\end{tabular}

Fonte: Dados da pesquisa.

Todos os estudos citados no Quadro 4 abordam de alguma forma a questão da necessidade de identificação e mensuração do CI para sua gestão. Dos seis artigos, três abordam o setor público/ sem fins lucrativos e três tratam de empresas privadas.

\section{METODOLOGIA DA PESQUISA}

A pesquisa é exploratória com a utilização de estudo de caso, levantamento (survey) e análises qualitativas e quantitativas (estatística descritiva), conforme ensinamentos de Collins e Hussey (2005) e Yin (2010).

Em seguida à produção do referencial teórico, e de acordo com o preconizado por Yin (2010), confeccionou-se um protocolo de estudo de caso contendo uma visão geral do projeto, onde foram definidas as questões de estudo e procedimentos de campo para a coleta de dados. Um dos autores deste artigo trabalhou como auditor na Unidade no ano de 2012 o que facilitou o entendimento do funcionamento da organização, acesso aos entrevistados e dados pesquisados, além de, conforme Yin (2010), proporcionou clara noção dos assuntos em estudo. A incidência em possíveis vieses foi mitigada pelo relato dos achados preliminares, ainda na fase de coleta de dados, a outros pesquisadores criteriosos, conforme orienta Yin (2010), a fim de se buscar possíveis alternativas e sugestões distintas das primeiras impressões encontradas.

Cada questão formulada no protocolo foi acompanhada das prováveis fontes de evidência (entrevistados, documentos etc), buscando-se manter a conexão entre as questões de estudo (do protocolo) e as perguntas aplicadas aos entrevistados (auditores e gestores militares) (YIN, 2010). A coleta de dados ocorreu entre novembro de 2014 e fevereiro de 2015 e foi planejada de forma a extrair informações a partir de entrevistas realizadas com auditores e gestores da unidade pesquisada, a mapear as rotinas de trabalho e a identificar as habilidades e competências necessárias a realização das auditorias. A partir desses dados e com base nos depoimentos, foram pesquisados documentos produzidos e sistemas baseados em TI utilizados pela unidade pesquisada.

Para organizar dentro da lógica da pesquisa e facilitar a compreensão dos depoimentos, foi desenhada matriz de análise de conteúdo, conforme Bardin (2011), com vistas a se analisar de acordo com o referencial teórico as perguntas e respostas dadas por auditores e gestores às entrevistas. As informações colhidas foram contrapostas às respostas de questionário aplicado aos auditados. Portanto, buscou-se confirmar junto aos auditados (externamente) os dados colhidos internamente na unidade de auditoria. Para isso, o questionário foi aplicado em todas as 76 unidades auditadas, contendo 40 questões que buscaram captar a percepção do auditado sobre o nível de competência do auditor com quem teve contato. 
As competências exploradas neste estudo basearam-se na pesquisa de Camargo (2012) e foram divididas em habilidades intelectuais, habilidades pessoais, habilidades interpessoais e de comunicação, e habilidades organizacionais e de gestão de negócios. Camargo (2012) pesquisou como as competências do auditor independente listadas na literatura são percebidas pelos auditados. A pesquisa foi voltada ao auditor independente, no entanto, conforme a autora deixa claro durante o estudo, aplica-se igualmente a todos os experts em auditoria, independente do setor de atuação.

A aplicação deste questionário deu-se a partir de um formulário on line do Google ${ }^{\mathrm{TM}}$ Docs e buscou a impressão de gestores alocados em setores de compras, financeiro, pessoal, ordenadores de despesa e fiscais administrativos, distribuídos em 66 unidades com caráter estritamente bélico (infantaria, cavalaria, artilharia etc), 6 seis organizações de saúde (hospitais e policlínica), duas unidades técnicas de engenharia (obras e levantamento cartográfico) e dois estabelecimentos de ensino fundamental $\left(5^{\mathrm{a}}\right.$ a $9^{\mathrm{a}}$ série $)$ e médio, em que obtiveram-se 138 respostas válidas.

Foi utilizada a escala likert de 5 pontos em que os respondentes avaliaram a afirmação sobre a existência de determinada competência do auditor da seguinte forma: (1) discordo totalmente, ou seja o auditor de forma alguma possui aquela competência; (2) discordo, em que o auditado entende que o auditor não tem a competência; (3) nem concordo, nem discordo, em que a afirmação não pôde ser avaliada pelo auditado; (4) concordo, em que o auditado percebeu a competência na situação vivenciada junto ao auditor; e (5) concordo totalmente em que o auditado está certo que o auditor tem aquela competência. Utilizou-se da estatística descritiva com foco na média das respostas encontradas para análise dos dados.

O questionário não fez distinção entre os tipos de unidades (bélica, saúde ou engenharia) ou entre as funções exercidas pelos profissionais de administração pública auditados (compras, financeiro etc) o que pode ser considerada uma limitação tendo em vista especificidades encontradas na auditoria de cada uma delas. Tal opção de pesquisa teve por objetivo colher uma impressão geral dos auditados integrantes da Instituição sobre o auditor, uma vez que tal percepção pode ter se formado em diversos momentos da vida profissional do auditado (o auditado que hoje trabalha em unidade bélica pode ter uma percepção do auditor de um momento anterior em que trabalhou na área de saúde e vice-versa).

Por fim, de posse dos dados sobre o CI (identificação, pontos fortes e fracos, mensuração, registro e gestão) e, com base na literatura, foi apresentado um modelo para mensuração e registro do CI.

\section{RESULTADOS E DISCUSSÃO}

\subsection{CARACTERIZAÇÃO DA UNIDADE PESQUISADA}

A unidade pesquisada é uma das onze seções de auditoria interna do EB distribuídas pelo território nacional e é responsável por auditar 76 organizações militares gestoras de recursos públicos. Possui treze auditores responsáveis por auditar unidades militares com autonomia para a gestão de recursos públicos, com missões bélicas (defesa), logística, de saúde, de ensino e engenharia.

São três auditores com mais de dez anos de vivência profissional em auditoria interna e apenas dois, em experiência, com menos de três anos em assuntos correlacionados. Nove são contadores, dois administradores e dois graduados em ciências militares. A equipe é chefiada por um auditor contador com mais de vinte anos de trabalho na auditoria interna do EB.

A partir dos dados advindos das entrevistas, da análise de conteúdo dos relatórios gerados pelos auditores após as atividades de auditoria e do documento que consolida o planejamento anual indicando quais unidades serão auditadas (PAAA- Plano Anual das 
Atividades de Auditoria), constatou-se o seguinte modus operandi por parte da unidade pesquisada:

(i) a priorização das unidades selecionadas para sofrerem auditoria baseia-se em uma matriz de risco que considera a materialidade e a relevância;

(ii) a quantidade de auditores, o número de unidades a serem auditadas (76) e a distância a ser percorrida (da capital ao interior do estado) limitam as visitas ao máximo de duas anuais para as unidades com maior risco e ao mínimo de uma a cada dois anos para as de menor risco;

(iii) cada visita de auditoria programada é feita em no máximo dois dias, no caso de unidades complexas como hospitais, e no mínimo um dia, nas de baixo risco, por equipes compostas de dois ou três auditores;

(iv) além das visitas previamente planejadas no PAAA, são realizadas auditorias especiais e tomadas de contas especiais para apurar indícios de irregularidades surgidos a partir de denúncias ou achados relevantes;

(v) o Manual de Auditoria do EB regula todo o modus operandi da unidade pesquisada;

(vi) a Unidade mensura seus custos por meio de um sistema próprio (Siscustos) acumulando-os nos centros de custos Atividade de Auditoria de Pessoal, Atividade de Planejamento e Estudos de Auditoria, Atividade de Auditoria e Avaliação de Gestão, Atividade de Relações Internas e Externas em Auditoria;

(vii) a Unidade faz uso intensivo de TI para pesquisa de dados sobre os auditados (Sistema de Auditoria Interna - SISAUD, Sistema de Acompanhamento de Danos ao Erário SISADE)

Verificou-se que a Unidade possui como visão de futuro ser referência em termos de controle interno no âmbito da administração pública e que tem como diretrizes manter e aprofundar suas relações institucionais (capital relacional), implementar processos e tecnologias eficazes e eficientes para o controle (capital estrutural) e aprimorar o seu capital humano (3 ${ }^{\text {a }}$ ICFEx, 2014).

\subsection{CAPITAL INTELECTUAL IDENTIFICADO NA UNIDADE PESQUISADA}

A partir das respostas obtidas com base na pergunta do questionário semiestruturado que direcionou as entrevistas (A sua experiência prévia contribui para realizar a função de auditor? Descreva como.), foi constatado que as contratações de novos auditores não exigem experiência prévia em atividades de auditoria. Apenas dois, dos treze auditores, possuíam experiência anterior, sendo um em empresas privadas e outro no próprio EB, em outra unidade de auditoria. Por outro lado, verificou-se que a Unidade contrata funcionários com experiência prévia de três anos ou mais em temas correlatos à atividade de auditoria ligados às áreas em que serão empregados como auditores (administração financeira, tesouraria, licitações e contratos, gestão de estoques, etc.), conforme previsto pelo IFAC (2014), a fim de constituir seu capital humano/ competência da empresa (SVEIBY, 1998; GUTHRIE; STEANE; FARNETI, 2009; MALAVSKI; LIMA; COSTA., 2010, VELTRI, 2014).

Identificou-se a existência de auditores mais experientes e capacitados, componentes do capital humano/ competência da empresa (SVEIBY, 1998; GUTHRIE; STEANE; FARNETI, 2009; MALAVSKI; LIMA; COSTA., 2010, VELTRI, 2014), que passam conhecimento aos iniciantes, situação em que confirma a existência de trabalho em equipe, conforme elencado pelo IIA (2012). O Quadro 5 apresenta as respostas dos auditores à questão formulada com propósito de verificar existência deste CI. 
Quadro 5: Respostas dos auditores à questão: utiliza-se do conhecimento dos demais auditores? É fácil acessar este conhecimento? Explique como é possível acessá-lo?

Sim, conversas, debates

Sim. Utilizo e acesso facilmente esses meios

Sim. Geralmente interna. Em conversas com auditores experientes.

Utilizo consultas diretas ou banco de dados com impropriedades já detectadas.

Sim, existe um bom relacionamento entre os auditores de forma que os conhecimentos são facilmente compartilhados. Debates eventuais.

Sim. Através de debates, conversas. Há um bom relacionamento entre colegas, o que facilita o acesso.

Atualmente, mais auxilio do que utilizo do conhecimento deles, sem no entanto abdicar de novas informações obtidas pelos colegas para melhoria dos trabalhos

Utilizo e é fácil ter acesso pelas reuniões, conversas informais

O convívio no ambiente de trabalho proporciona a troca de informações oriundas da participação dos auditores em conferência, seminários, cursos, palestras, etc.

A auditoria é um compartilhamento de ideias, seja por conversas, debates. De fácil acesso pela boa convivência com os colegas.

O acesso é direto ao colega, porém sinto falta de reuniões e encontros formais

Sim, há uma grande troca de ideias com os colegas, para padronizar os trabalhos. É de fácil acesso, através de conversas, debates.

Sim, através de conversas, debates. De fácil acesso.

Fonte: Dados da pesquisa.

O meio militar exercita e cobra através da disciplina, desde o início da formação de seus quadros, valores éticos que são exigidos como obrigação profissional em um ambiente que valoriza o patriotismo, a honra, a disciplina e a lealdade, conforme constatado in loco e por meio de entrevistas. Além disso, verificou-se a prática dos auditores assinarem um termo de confidencialidade que permanece arquivado e pode ser usado por via judicial (Justiça Militar) no caso de uso indevido das informações colhidas ao longo dos trabalhos de auditoria. Tudo isso foi identificado como capital humano/ competência da empresa e capital estrutural/ estrutura interna (SVEIBY, 1998; GUTHRIE; STEANE; FARNETI, 2009; MALAVSKI; LIMA; COSTA., 2010, VELTRI, 2014).

O banco de dados disponibilizado pela Unidade para consultas dos auditores, previsto no Manual de Auditoria do EB, foi identificado in loco como capital estrutural/ estrutura interna como preconizado na gestão do CI pelo modelo VBR (SVEIBY, 1998; GUTHRIE; STEANE; FARNETI, 2009; MALAVSKI; LIMA; COSTA., 2010, VELTRI, 2014). O acesso ao banco de dados é feito por meio de rede integrada em que cada auditor, por meio de computador individual disponibilizado pela Unidade, busca as informações até um nível autorizado.

A Unidade possui uma metodologia de trabalho própria, baseada no Manual de Auditoria do EB, estruturada em processos padronizados que foram certificados com o Prêmio Gaúcho de Qualidade e Produtividade. O planejamento institucional para as atividades de auditoria é sistematizado, conforme previsto no Manual de Auditoria do EB, por meio do Plano Anual de Atividades de Auditoria (PAAA), tendo por base modelos de papéis de trabalho para cada área auditada (pagamento de pessoal, licitações e contratos, etc.). Estas sistematizações nos procedimentos de auditoria (processos padronizados e planejamento) são consideradas capital estrutural na ótica da VBR (MALAVSKI; LIMA; COSTA., 2010) e estrutura interna na classificação de Sveiby (1998) e Guthrie, Steane e Farneti (2009).

A construção da relação da unidade pesquisada com os auditados e com órgãos públicos que trocam dados referentes às unidades auditadas (Tribunais de Contas, Justiça Militar, Consultoria Jurídica e outros órgãos de controle) formam o capital relacional/ estrutura 
externa prescritos pela VBR (MALAVSKI; LIMA; COSTA., 2010) e por Sveiby (1998) e Guthrie, Steane e Farneti (2009). Essa relação foi construída ao longo do tempo por meio de reuniões, acordos de cooperação, estudos conjuntos, dentre outras formas de aprofundar o conhecimento institucional entre as entidades.

\subsection{GESTÃO DO CAPITAL INTELECTUAL NA UNIDADE PESQUISADA}

A unidade pesquisada não concentra informações sobre a gestão do CI em relatórios ou demonstrativos semelhantes aos modelos citados por Guthrie, Steane e Farneti (2009) e em complemento às demonstrações exigidas pela Lei 4.320/64. Por sua vez, também não realiza controle por meio de indicadores ou valores numéricos/ monetários com vistas a aferir o resultado do seu trabalho, conforme preconiza Antunes (2006) ou por meios qualitativos como BSC, ERP, EVA ou aplicativos próprios (ALVARENGA; BARBOSA; PEREIRA, 2007).

Verificou-se, ainda, que o controle financeiro sobre os investimentos em CI não se realiza de forma agregada em um único centro de custos capaz de demonstrar o esforço financeiro dispendido com vistas a se aprimorar a capacitação dos auditores. Assim, no caso de se realizar um treinamento internamente, conduzido pelos próprios auditores, os gastos que deveriam ser agregados separadamente são acumulados como atividade de auditoria o que gera uma distorção na informação necessária à gestão do CI.

Portanto, a Unidade não contabiliza de forma separada o CI ou, usando a expressão "lock-in" de Chiucchi e Dumay (2015), não faz uso de práticas contábeis com vistas a identificar, mensurar e registrar seu CI. No entanto, verificou-se ao longo das entrevistas e observação in loco, que o CI é percebido e gerenciado de forma intuitiva pelos gestores, conforme as evidências a seguir relatadas.

Conforme Imoniana, Matheus e Perera (2014), o grupo de auditores deve receber investimentos em treinamento de modo a se manter atualizado com as melhores práticas. A atualização de conhecimentos na Unidade segue um processo semiestruturado em que é feita uma previsão anterior de capacitação dos auditores, porém não foi diagnosticado um rito padrão, alinhado com as necessidades do trabalho de auditoria. Cinco dos treze auditores informaram que não há treinamento de atualização, sete responderam que há cursos e treinamentos eventuais e um respondeu que há com periodicidade. Estas declarações conflitantes foram esclarecidas pelo chefe da seção de apoio e treinamento da unidade pesquisada, responsável pela atualização de conhecimentos da Unidade, que confirmou não haver um processo padrão para levantamento das necessidades em atualização de conhecimentos. O oficial declarou que se busca garantir com antecedência no orçamento anual os recursos necessários à participação dos auditores em eventos e treinamentos, porém a demanda parte do próprio auditor, ouvido o chefe da Unidade.

O montante investido em eventos de capacitação (cursos, congressos, seminários etc) pagos a entidades externas e realizados dentro do próprio EB (matrículas em cursos e diárias e passagens) atingiu cerca de $\mathrm{R} \$ 170$ mil em 2013 e 2014 o que representou 5\% de todo o gasto da unidade de auditoria no período, conforme dados extraídos do sistema de custos da organização. Somam-se a estes custos, a capacitação gerada internamente dentro da própria unidade de auditoria, feita por meio de palestras e cursos no formato ensino à distância que não são capturados pelo sistema de custos. Estes investimentos retratam que os gestores da unidade pesquisada percebem a importância da capacitação, conforme previsto no Manual de Auditoria do EB, e em acordo com a exigência de educação continuada nesse tipo de atividade (IIA, 2012). A capacitação dos auditores inclui mestrado em ciências contábeis, especialização em contabilidade, auditoria, finanças governamentais, e controladoria, e cursos de extensão em licitações, contratos, contabilidade pública, auditoria, avaliação e modelagem 
de projetos, uso de ferramentas tecnológicas, tudo conforme as competências requeridas ao auditor (IFAC, 2014).

A Unidade não realiza treinamento específico para os novos auditores (recémcontratados), proporcionando, apenas, acompanhamento a dois ou três trabalhos de campo feitos por auditores experientes, antes de serem enviados para a realização de auditorias. Os auditores recém-contratados, após assistirem aos trabalhos de campo, passam a realizar auditorias de áreas menos complexas e, à medida que ganham experiência, são inseridos em trabalhos mais complexos. Os novatos fazem cursos, porém de acordo com a disponibilidade da agenda de capacitação. Assim, dependendo da época em que o novato é contratado e da programação de auditoria, poderá ser escalado em trabalhos de campo na condição de aprendiz e só depois receberá treinamento formal em sala de aula. Tal procedimento não coaduna com a maioria das normas que preveem habilidades técnicas e experiência profissional como características do auditor (SARENS, 2009).

Foi verificada a ocorrência de mudanças nos componentes das equipes de auditoria em função de exigência da legislação militar que prevê transferência geográfica (cidade ou estado) após um período mínimo de dois anos servindo em um local, o que poderia provocar prejuízo ao trabalho de auditoria. De acordo com relato dos auditores entrevistados, tal prática não prejudica o desempenho da Unidade, pois parte dos auditores, em função da experiência na área, não são transferidos, formando uma coluna de sustentação para os recém-chegados.

O tempo médio dos auditores na função é de oito anos, estando o mais experiente com 24 anos de serviço e a mais recente contratação feita há um ano. O gestor da unidade de auditoria tem conseguido manter uma equipe com boa experiência ao longo dos anos o que demonstra percepção com relação à manutenção da dimensão humana do CI, conforme Sveiby (1998), Edvinson e Malone (1998). Por outro lado, verifica-se que o baixo índice de novos contratados (2 em um universo de 13) pode trazer prejuízos à dimensão inovação, conforme Edvinson e Malone (1998).

Constatou-se uma lacuna de conhecimento na capacitação da maioria dos auditores no que se refere aos trabalhos de auditoria realizados em organizações de saúde e engenharia. Cerca de $60 \%$ relataram não serem capacitados para auditarem hospitais e obras civis, pois são compostos por insumos de alta complexidade técnica. No que se refere às organizações que tratam especificamente de atividades bélicas, os auditores entrevistados não informaram terem dificuldades, conforme relato: "quando audito uma unidade de combate me sinto mais à vontade, pois conheço toda a rotina em função da minha experiência como militar; o mesmo não acontece quando audito uma internação de alto custo, com uso de medicamentos e procedimentos médicos complexos".

Observou-se, ainda, pela análise dos relatórios de auditoria que os auditores possuem um conhecimento voltado para a fiscalização da gestão no atendimento ao previsto nas normas de contabilidade pública; no entanto, aspectos ligados a qualidade da gestão foram pouco observados o que reforça a percepção fiscalizatória encontrada em alguns depoimentos dos auditados, conforme Lelis e Pinheiro (2012).

Com o objetivo de confirmar a lacuna de competência em determinadas áreas do conhecimento por parte dos auditores, foi buscada a percepção dos auditados sobre habilidades intelectuais e organizacionais e de gestão de negócios. A Tabela 1 apresenta o resultado das respostas dos auditados, colhidas por meio de questionário, sobre a percepção que têm das competências dos auditores (habilidades intelectuais e organizacionais e de gestão de negócios). 
Tabela 1 - Dados descritivos da percepção do auditado sobre as competências intelectuais e organizacionais e de gestão de negócios do auditor

\begin{tabular}{|c|c|c|c|c|c|c|c|}
\hline \multirow{2}{*}{$\begin{array}{l}\text { Competências do Auditor } \\
\text { Habilidades Intelectuais }\end{array}$} & \multicolumn{7}{|c|}{ Estatística Descritiva } \\
\hline & $\mathrm{N}$ & $\mathrm{M}$ & MM & MD & MA & $\mathrm{MO}$ & $\mathrm{DP}$ \\
\hline Raciocínio crítico & 138 & 1 & 5 & 4,029 & 4 & 4 & 0,828 \\
\hline Habilidades de Pesquisa & 138 & 2 & 5 & 4,035 & 4 & 4 & 0,496 \\
\hline Habilidade de Coleta de Dados & 138 & 2 & 5 & 4,152 & 4 & 4 & 0,763 \\
\hline Habilidades de Investigação & 138 & 2 & 5 & 4,137 & 4 & 4 & 0,766 \\
\hline Resolução de Problemas & 138 & 1 & 5 & 3,869 & 4 & 4 & 0,963 \\
\hline Capacidade de Fazer Exceções & 138 & 2 & 5 & 3,746 & 4 & 4 & 0,854 \\
\hline Habilidades Analíticas & 138 & 2 & 5 & 3,768 & 4 & 4 & 0,766 \\
\hline Inteligência & 138 & 2 & 5 & 3,920 & 4 & 4 & 0,828 \\
\hline Raciocínio Rápido & 138 & 1 & 5 & 3,833 & 4 & 4 & 0,798 \\
\hline Processamento Multivariado & 138 & 3 & 5 & 3,891 & 4 & 4 & 0,771 \\
\hline Percepção & 138 & 2 & 5 & 3,761 & 4 & 4 & 0,806 \\
\hline Pensamento Lateral & 138 & 2 & 5 & 3,579 & 4 & 4 & 0,827 \\
\hline Capacidade Identif. Infor. relevantes & 138 & 1 & 5 & 3,863 & 4 & 4 & 0,872 \\
\hline Julgamento profissional & 138 & 1 & 5 & 4,05 & 4 & 4 & 0,882 \\
\hline $\begin{array}{l}\text { Habilidades organizacionais e de } \\
\text { gestão de negócio }\end{array}$ & & & & & & & \\
\hline Foco no cliente & 138 & 1 & 5 & 3,833 & 4 & 4 & 0,986 \\
\hline Liderança & 138 & 2 & 5 & 4,341 & 4 & 4 & 0,739 \\
\hline
\end{tabular}

Legenda: N=Número de Respondentes; M=Mínimo; MM=Máximo; MD=Média; MA=Mediana; MO=Moda; DP=Desvio Padrão.

Fonte: Dados da Pesquisa com base em Camargo (2012).

A Tabela 1 revela competências com média acima de 3 (escala 1-5), variando entre 3,579 para a competência "pensamento lateral" e 4,152 para "habilidade de coleta de dados". O ponto máximo atribuído pelos respondentes para todas as competências foi de 5 (valor máximo da escala utilizada), e variou entre 1 e 2 para os pontos mínimos. O desvio padrão ficou abaixo de 1, demonstrando baixa variabilidade na percepção dos respondentes, o que em outras palavras representa baixa discrepância entre as respostas no conjunto da pesquisa.

As competências "raciocínio crítico", "habilidades de pesquisa", liderança e "foco no cliente" tiveram média 4,029 e 4,035, 4,341 e 3,833, respectivamente. As competências "habilidade de coleta de dados", "habilidade de investigação" e "julgamento profissional também obtiveram média acima de 4 . As demais habilidades atingiram média entre 3,863 ("capacidade de identificar informações relevantes") e 3,891 ("processamento multivariado").

As demais competências (pessoais, interpessoais e de comunicação) apresentaram extremos (maiores e menores médias) nas seguintes habilidades:

Tabela 2 - Dados descritivos da percepção do auditado sobre as competências pessoais e interpessoais e de comunicação do auditor (maior média e menor média)

\begin{tabular}{|c|c|c|c|c|c|c|c|c|}
\hline \multirow{2}{*}{\multicolumn{2}{|c|}{$\begin{array}{l}\text { Competências do Auditor } \\
\text { Habilidades Pessoais }\end{array}$}} & \multicolumn{7}{|c|}{ Estatística Descritiva } \\
\hline & & $\mathrm{N}$ & $\bar{M}$ & MM & MD & MA & $\mathrm{MO}$ & DP \\
\hline Ceticismo Profissional & & 138 & 3 & 5 & 4,254 & 4 & 4 & 0,673 \\
\hline Persistência & & 138 & 1 & 5 & 3,710 & 4 & 4 & 0,785 \\
\hline $\begin{array}{l}\text { Habilidades interpessoais } \\
\text { comunicação }\end{array}$ & de & & & & & & & \\
\hline Trabalho em Equipe & & 138 & 2 & 5 & 4,087 & 4 & 4 & 0,749 \\
\hline Relacionamento Interpessoal & & 138 & 1 & 5 & 3,833 & 4 & 4 & 0,851 \\
\hline
\end{tabular}

Fonte: Dados da Pesquisa com base em Camargo (2012).

Do exposto e com base na descrição das habilidades feita por Camargo (2012), os dados, de uma maneira geral, expressam que os auditados não percebem as lacunas de 
competência citadas pelos auditores nas entrevistas. Verifica-se pelo conjunto dos dados (média e variância) que o trabalho dos auditores é considerado de bom nível pelos auditados.

Sarens (2009) observa a necessidade de os procedimentos de auditoria preverem pesquisa de satisfação com os auditados, programa de qualidade e melhoria e se são objeto de análise externa. Verificou-se a previsão de pesquisa de satisfação do auditado no Manual de Auditoria do EB, realizada por meio de um questionário que avalia a qualidade do trabalho da equipe de auditoria. A unidade de auditoria sofre avaliação externa por parte de auditores lotados no Centro de Controle Interno do Exército (CCIEx), localizado em Brasília, que se processa de forma remota (verificação de relatórios de auditoria, prestações de contas, etc.) e presencial, a cada dois anos. Não foi observada a existência de programa de qualidade e melhoria voltados para a atividade de auditoria.

Destaca-se que a prática de avaliação externa e auto avaliação, apesar de prevista no Manual de Auditoria do EB, não é feita de forma sistematizada. Grande parte dos auditores entrevistados relataram que ressentem a falta de crítica ao resultado dos trabalhos de auditoria. Até mesmo os questionários que são enviados à unidade de auditoria, contendo a percepção dos auditados após um trabalho de campo, não são disponibilizados aos auditores. Percebeu-se pelos relatos que os auditores não possuem um feedback de seu trabalho de campo. Nem mesmo o resultado do trabalho de auditoria em termos de economia advinda da descoberta de fraudes ou erros não é medido e comparado em períodos distintos, conforme Antunes (2006) preconiza. A ausência de críticas ao trabalho de auditoria pode ser constatada pela resposta dos auditores à questão da entrevista.

Quadro 6 - Respostas dos auditores à questão: após um trabalho de auditoria, qual a frequência em que os relatórios contendo os achados e orientações sofrem críticas?

Não é comum os relatórios sofrerem críticas negativas e necessidade de retrabalho. Raramente em uma auditoria especial foi pedida complementação de informações Até o momento não soube de nenhuma crítica Raramente há problemas nos relatórios Durante a experiência na Seção de Auditoria, não presenciei rejeição de relatórios pelo CCIEX Não recordo do CCIEX ter criticado algum relatório confeccionado pela ICFEX Não presenciei críticas (não foi tomado conhecimento)

Dificilmente. Em geral não há crítica

Nenhuma

Os relatórios são enviados ao CCIEx, somente para arquivar e não sofrem crítica Fonte: Dados da pesquisa.

Foi constatado que os auditores se utilizam sistematicamente de reuniões junto aos gestores das organizações auditadas após os trabalhos de campo para discussão dos principais aspectos observados. Este procedimento é previsto no Manual de Auditoria do EB e é salientado por Sarens (2009) como boa prática. Esta ação reforça o capital relacional com os clientes da unidade pesquisada (organizações militares auditadas), que compõe o CI da organização.

A unidade pesquisada não exige que seus auditores realizem avaliações constantes com vistas a se aferir e comprovar o conhecimento profissional periodicamente e nem mesmo são exigidas certificações de entidades reconhecidas nacional ou internacionalmente na área de auditoria ou afins, como o IIA, a Audibra (Instituto dos Auditores Internos do Brasil), o AICPA (Instituto Americano de Contadores Públicos Certificados) ou o IMA (Institute of Management Accountants) o que caracterizaria uma oportunidade de construir capital humano/ competência da empresa e capital estrutural/ estrutura interna. 
Por fim, verificou-se que o banco de dados de apoio, identificado como capital estrutural, contém acervo atualizado de normas (leis, decretos, portarias), relatórios de auditoria emitidos, achados de auditoria, prestações de contas, relatórios de gestão das unidades auditadas, dentre outros. A manutenção deste banco de dados demanda sacrifício financeiro que são custos intangíveis necessários ao suporte de equipe dedicada na análise e programação, aquisição de softwares e capacitação em redes.

\subsection{DISCUSSÃO ACERCA DE UM MODELO DE CONTABILIZAÇÃO E GESTÃO DO CI}

De acordo com Chiucchi e Dumay (2015), há uma discussão em aberto sobre a afirmação de que uma perspectiva dominante com foco na contabilização (mensuração e registro) do CI pode desvirtuar os processos que envolvem sua gestão. No entanto, tal discussão não aponta para a gestão do CI sem a necessidade de se realizar qualquer tipo de mensuração e registro, apenas por meio de intuição, como visto na unidade pesquisada.

Considerando o modelo de gestão do CI aplicado pelo EB na unidade pesquisada, conforme apresentado na seção anterior, abre-se caminho para discutir possibilidades de implantação de um novo modelo de gestão com base em um sistema de mensuração e registro conforme apresentado pela literatura. Acredita-se que a implantação do modelo sugerida nesta seção aumente a possibilidade de alinhamento da gestão do CI com a estratégia organizacional.

Identificados os fatores componentes do CI da Unidade e considerando o fato de as informações (quantidades e montantes) estarem à disposição, conforme preconiza Chiucchi e Dumay (2015), apresenta-se a Figura 1 que busca resumir o objetivo do modelo em um formato amplo.

Figura 1 - Objetivo do Modelo

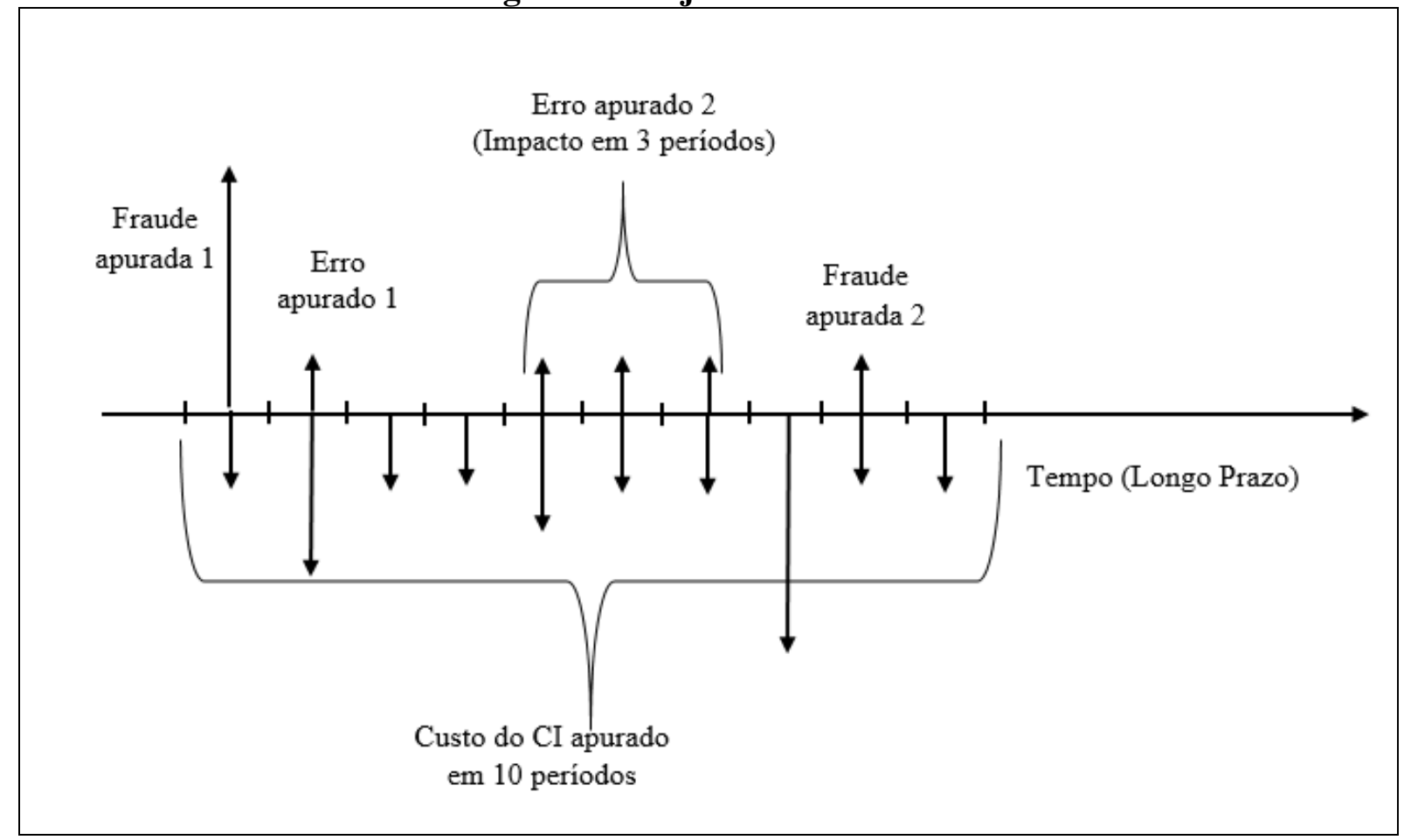

Fonte: Dados da pesquisa.

O objetivo do modelo é confrontar o custo do CI apurado (seta para baixo) com o valor estimado do valor "salvo" a partir da identificação de fraudes e erros (seta para cima). A 
confrontação, no longo prazo, vai dar um panorama do resultado do investimento em CI. No caso dos erros, considera-se o trabalho de assessoramento do controle interno com vistas a indicar à administração auditada um caminho para a gestão eficiente, distinto do utilizado.

Portanto, para se atingir este objetivo, é necessário identificar, medir e registrar o custo do CI na Unidade e o valor "salvo" a partir da identificação de fraude e erros. Considerado o CI identificado na Unidade e o requerido para a atividade de auditoria, conforme a literatura e órgãos reguladores da profissão, propõe-se o seguinte modelo:

\section{Figura 2 - Modelo para mensurar e registrar o CI}

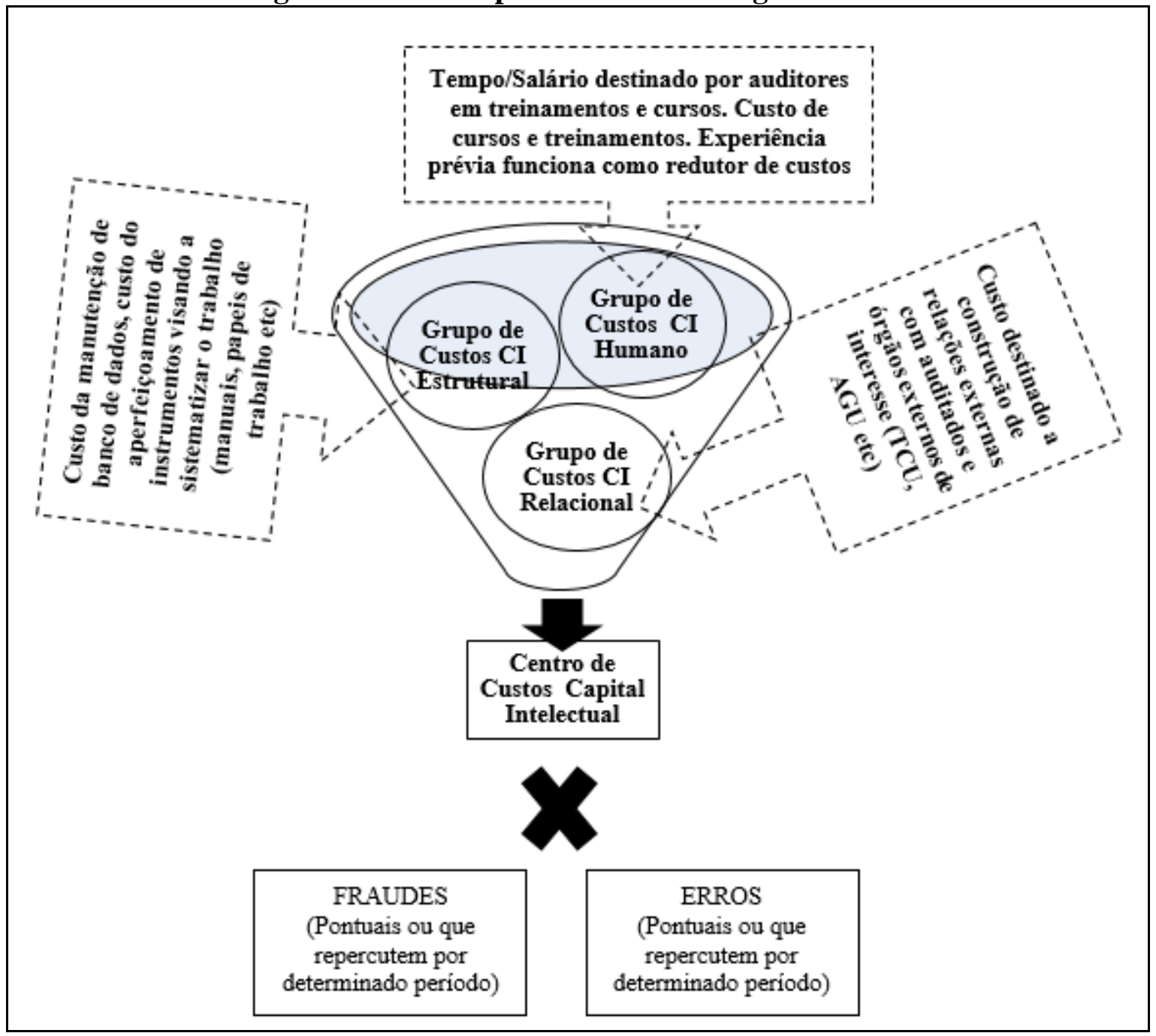

Fonte: Dados da pesquisa.

A Figura 2 propõe um modelo em que o custo do CI é acumulado em um centro de custos (CC) que pode ser criado no sistema utilizado pela Unidade (Siscustos). Este CC dividir-se-ia em 3 grupos de custos (humano, relacional e estrutural) baseados nos fatores identificados como CI da Unidade. O custo do CI, calculado automaticamente pelo Siscustos, será confrontado com as fraude e erros conforme a Figura 1. As fraudes/ erros pontuais, como licitações com sobrepreço na aquisição de um bem, ao serem descobertas, têm seu valor acima de mercado computado como um fluxo de caixa positivo a ser confrontado em uma única vez com o custo do CI no período analisado. As fraudes/ erros descobertos que repercutem por determinado período, como um contrato de prestação de serviços cujo cálculo 
apresentava um valor a maior a ser pago em 3 parcelas devem ser confrontadas com o custo do CI naqueles mesmos 3 períodos.

\section{CONSIDERAÇÕES FINAIS}

As duas grandes teorias contemporâneas (Razão Market-to-Book do CI e Relação Disclosure do CI e rentabilidade) que sustentam a necessidade da gestão do CI como fator relevante para a lucratividade e sustentabilidade das organizações, necessitam ter um enfoque mais empírico e deve-se evitar a generalização de sua aplicação sob pena de se cair em armadilhas. Aplicadas ao setor público, tais teorias devem ser adaptadas de forma a considerar o fim não-lucrativo a que se destinam.

No caso estudado, foram identificados aspectos positivos no que se refere ao CI e sua gestão: (i) capital humano estruturado como o núcleo do CI; (ii) uso intensivo de TI para acelerar a difusão e uso do conhecimento; e (iii) sistematização de procedimentos.

No entanto, a unidade pesquisada não identifica e faz a gestão do CI utilizando-se de um sistema de medição com monitoramento integrado de seu desenvolvimento. Para a Unidade, o CI está disperso pela organização que o trata de forma departamentalizada.

O capital estrutural apresenta deficiência, sobretudo por não ser capaz de alavancar o processo de inovação, como verificado no trabalho de Santos-Rodrigues et. al (2013) o que poderia conduzir a Unidade ao planejamento e execução de procedimentos de auditoria baseados em risco, com foco na gestão e menos legalista. Tal situação pode ser consequência de um sistema de avaliação deficiente e ausência de metodologia capaz de medir a criação de valor por parte do CI.

O sistema de avaliação precisa de aperfeiçoamento com vistas a conduzir a Unidade a uma melhoria contínua dos processos. As lacunas de conhecimento criam vulnerabilidades e, portanto, aumentam o risco do $\mathrm{EB}$ na gestão de recursos públicos. A Unidade não mede o valor criado pelo seu CI, perdendo-se a oportunidade de se acompanhar a relação entre investimento em CI e ganhos econômicos advindos da intervenção do trabalho de auditoria em ações danosas (fraudes e erros) por parte das unidades auditadas.

A partir das constatações sobre a forma como a Unidade faz a gestão de seu CI e com base na literatura, sobretudo em modelos aplicados em organizações sem fins lucrativos, foi proposto um modelo que se entende como adequado aos propósitos da Instituição. A implementação desse modelo pode ser feita a baixo custo por meio de adaptações no sistema de custos utilizado pela Unidade.

Sugere-se que trabalhos futuros apresentem modelos para a medição da criação de valor pelo CI na auditoria interna ou que os apliquem nas unidades de controle interno do setor público e sejam estudados os processos de implantação ou a evolução dos resultados em auditorias a partir da aderência aos novos modelos.

\section{REFERÊNCIAS}

$3^{\text {a }}$ ICFEx - $3^{\text {a }}$ Inspetoria de Contabilidade e Finanças do Exército (2014). Missão, valores, visão de futuro e diretrizes para a $\mathbf{3}^{\mathbf{a}}$ ICFEx. Disponível em < www.3icfex.eb.mil.br/index.php?content=missao>. Acesso em 18 Jan 2015.

ALVARENGA, R. C. D. N.; BARBOSA, R. R.; PEREIRA, H. J. Gestão do conhecimento ou gestão de organizações da era do conhecimento? Um ensaio teórico-prático a partir de intervenções na realidade brasileira. Perspectivas em ciência da informação, v. 12, n. 1, p. $5-24,2007$. 
ALVES, A.C.; SILVA, S. F.; RAMALHO A.M.C.; GOMES, A.V. Análise e Mensuração da Gestão do Conhecimento e Capital Intelectual nas Organizações: estudo de caso em uma empresa de contabilidade. Pensamento \& Realidade, v. 29, n. 4, p. 22-41, 2014.

ALVES, J.J.S. Auditoria no sector público: uma análise ao sistema português. Lusíada. Economia e Empresa, v. 16, n. 1, p. 75-104, 2013

ANTHONY, R. N.; GOVINDARAJAN, V. Management control systems. 12. Ed. New York: Irwin McGraw-Hill, 2007.

ANTUNES, M. T. P. A controladoria e o capital intelectual: um estudo empírico sobre sua gestão. Revista Contabilidade \& Finanças, v. 17, n. 41, p. 21-37, 2006.

BARDIN, L. Análise de conteúdo. São Paulo: Edições 70, 2011.

BRASIL. Tribunal de Contas da União. Critérios gerais de controle interno na administração pública: um estudo dos modelos e das normas disciplinadoras em diversos países, Brasília, 2009. Disponível em: http://portal2.tcu.gov.br/portal/pls/portal/docs/2056688.PDF. Acesso em 18 dez. 2014.

_. Projeto de Lei Orçamentária 2014 (PLOA 2014). Disponível em: www.planejamento.gov.br/ministerio.asp?index=8\&ler=s798. Acesso em: 15 jan 2015.

Comando do Exército. Aprova o Manual de Auditoria do Exército. Portaria n. 018, de 17 de janeiro de 2013. Disponível em: http://www.3icfex.eb.mil.br/content/legislacao/arquivos/be4-13.pdf. Acesso em 28 Nov 2014.

CAMARGO, R. C. C. P. Competências do auditor: um estudo empírico sobre a percepção dos auditados das empresas registradas na CVM. 2012. 196 f. Dissertação (Mestrado em Ciências Contábeis) - Programa de Pós-graduação em Ciências Contábeis da Universidade Federal de Santa Catarina, Santa Catarina. 2012.

COLLIS, J.; HUSSEY, R. Pesquisa em administração: um guia prático para alunos de graduação e pós-graduação. Porto Alegre: Bookman, 2005.

CHIUCCHI, M. S.; DUMAY, J. Unlocking intellectual capital. Journal of Intellectual Capital, v. 16, n. 2, p. 305-330, 2015.

DIAS, M. A. H.; ZARELLI, P. R.; SELIG, P. M. Intellectual capital and public management: a bibliometric analysis. Journal of US-China Public Administration, v. 11, n. 2, p. 108$120,2013$.

DUMAY, J. C. Grand theories as barriers to using IC concepts. Journal of Intellectual Capital: v. 13, n 1, p. 4-15, 2012.

DUMAY, J.; GUTHRIE, J.; PUNTILLO, P. IC and public sector: a structured literature review. Journal of Intellectual Capital, v. 16, n. 2, p. 267-284, 2015. 
EDVINSSON, L.; MALONE, M. S. Capital intelectual: descobrindo o valor real de sua empresa pela identificação de seus valores internos. São Paulo: Makron Books, 1998.

FRANCINI, W. S. A gestão do conhecimento: conectando estratégia e valor para a empresa. RAE-eletrônica, v. 1, n. 2, 2002.

GUEDES, J. F., AGUIAR, A. S. A estrutura de controle interno e as ferramentas de controle do Exército Brasileiro. Revista Eletrônica S@aber, 26, (1). 2014.

GUTHRIE, J.; DUMAY, J. New frontiers in the use of intellectual capital in the public sector. Journal of Intellectual Capital, v. 16, n. 2, p. 258-266, 2015.

GUTHRIE, P. J.; STEANE, P.; FARNETI, F.. IC reporting in the Australian Red Cross blood service. Journal of Intellectual Capital, v. 10, n. 4, p. 504-519. 2009.

IFAC - INTERNATIONAL FEDERATION OF ACCOUNTANTS. International Education Standard 8 -Competence Requirements for Audit Professional. In: Handbook of International Education Pronouncements. New York: IFAC, 2014. Disponível em:: http://www.ifac.org. Acesso em: 20 set 2014.

IIA - Institute of Internal Auditors. The Role of Auditing in Public Sector Governence. In: Supplemental Guidance: The Role of Auditing in Public Sector Governance. Florida: IIA, 2012. Disponível em: https://na.theiia.org/standardsguidance/Public\%20Documents/Public_Sector_Governance1_1_.pdf. Acesso em 29 out 2014.

LÉLIS, D.M.; PINHEIRO, L.T. Percepção de auditores e auditados sobre as práticas de auditoria interna em uma empresa do setor energético. Revista Contabilidade \& Finanças: v. 23, n. 60, p. 212-222. 2012.

LIMA, J. P. C.; ANTUNES, M. T. P. Fatores relevantes para a gestão do capital intelectual sob a ótica da Visão Baseada em Recursos (VBR): um estudo baseado na percepção dos gestores da Sanofi Aventis Brasil. Sociedade, Contabilidade e Gestão, v. 7, n. 1, 2012.

MALAVSKIA, O. S.; LIMA, E. P.; COSTA, S. E. G. Modelo para a mensuração do capital intelectual: uma abordagem fundamentada em recursos. Produção, v. 20, n. 3, p. 439-454, 2010.

MASSINGHAM, P. R.; TAM, L. The relationship between human capital, value creation and employee reward. Journal of Intellectual Capital, v. 16, n. 2, p. 390-418, 2015.

POLO, F. C.; RODRÍGUEZ, C. R. Una revisión histórico-descriptiva de las empresas pioneras en el tratamiento de intangibles. Intangible Capital, v. 10, n. 1, p. 125-154, 2014.

RAMÍREZ, Y. Intellectual capital models in Spanish public sector. Journal of Intellectual Capital, v.11, n. 2, p. 248-264, 2010.

SANTOS-RODRIGUES, H.; FARIA, J.; CRANFIELD, D.; MORAIS, C. Intellectual Capital and Innovation: A Case Study of a Public Healthcare organisation in Europe. Electronic Journal Of Knowledge Management, v. 11, n. 4, p. 361-372, 2013. 
SARENS, G. Internal auditing research: where are we going? Editorial. International Journal of Auditing, v. 13, n. 1, p. 1-7, 2009.

STEWART, T. A. Capital intelectual: a nova vantagem competitiva das empresas. $4^{\mathrm{a}}$ ed. Rio de Janeiro: Campus, 1998.

SVEIBY, K. E. A Nova Riqueza das Organizações: gerenciando e avaliando patrimônios de conhecimento. Rio de Janeiro: Campus, 1998.

VAGNONI, E.; OPPI, C. Investigating factors of intellectual capital to enhance achievement of strategic goals in a university hospital setting. Journal of Intellectual Capital, v. 16, n. 2, p. 331-363, 2015.

VELTRI, S. Do stakeholder expectations shape organizational intellectual capital reports?. Knowledge \& Process Management, v. 21, n. 3, p. 177-186, 2014.

YIN, R. K. Estudo de caso: planejamento e métodos. 4 ed. Porto Alegre: Bookman, 2010. 